\title{
INFLUENCE OF COMPLEX TREATMENT ON BIOCHEMICAL BLOOD PARAMETERS OF PATIENTS WITH NON-ALCOHOLIC FATTY LIVER DISEASE AND CONCOMITANT PRE-DIABETES
}

DOI: 10.36740/WLek202104133

\author{
Snizhana V. Feysa, Svitlana O. Rudakova \\ STATE HIGHER EDUCATIONAL ESTABLISHMENT "UZHHOROD NATIONAL UNIVERSITY", UZHHOROD, UKRAINE
}

\begin{abstract}
The aim: 0 f this research is to evaluate laboratory changes in the liver blood tests, carbohydrate and lipid metabolism in NAFLD patients with concomitant pre-diabetes, and to study the feasibility of their complex treatment with the inclusion of omega-3 polyunsaturated fatty acids and essential phospholipids.

Materials and methods: We have examined 55 patients with non-alcoholic fatty liver disease on the background of pre-diabetes aged 40 to 75 years. Modification of lifestyle was recommended to all patients as a basic treatment. In addition, the patients were prescribed essential phospholipids in 2 capsules 3 times a day and omega- 3 polyunsaturated fatty acids $1000 \mathrm{mg}$ per day for 28 patients (group 1) or rosuvastatin $10 \mathrm{mg}$ per day for 27 persons (group 2). The effectiveness of the treatment was evaluated in 3 months, and the long-term outcomes were evaluated in 12 months.

Results: Under the influence of the prescribed treatment, a hypolipidemic effect was observed in both groups, but a significant decline in the activity of alanine aminotransferase and aspartate aminotransferase occurred only under the influence of a combination of essential phospholipids and omega-3 polyunsaturated fatty acids.

Conclusions: Thus, the described results allow to recommend this combination of medicines to patients with non-alcoholic fatty liver disease and concomitant pre-diabetes.
\end{abstract}

KEY WORDS: pre-diabetes; dyslipidemia; hepatoprotector; essential phospholipids; omega-3 polyunsaturated fatty acids

Wiad Lek. 2021;74(4):986-991

\section{INTRODUCTION}

Non-alcoholic fatty liver disease (NAFLD) is the most common chronic liver condition wordwide that begins with excessive accumulation of lipids in hepatocytes, mainly triglycerides (stage of hepatosteatosis) [1], after that it can progress to steatohepatitis [2] and very often predictors (obesity, type 2 diabetes mellitus, dyslipidemia, genetic predisposition) are present with NAFLD [3]. There are controversial views on the appropriateness of the prescribtion of medication in cases where NAFLD is diagnosed in patients with pre-diabetes (PD), characterized by a glucose intolerance or preprandial hyperglycemia, especially if the NAFLD is detected during the initial stage, i.e. hepatosteatosis. A dangerous feature of NAFLD, especially at the stage of steatosis, is the asymptomatic clinical picture, which makes it difficult to timely diagnose and initiate early treatment. Very often, the clinical picture of NAFLD patients is characterized only by the symptoms of concomitant pre-diabetes or type 2 diabetes mellitus (CD-2) (often first detected). Most scientificies tend to recommend lifestyle modification and dietary correction to treat such a comorbid combination. This pathogenetic approach is also well-grounded for hepatosteatosis (contributes to lower lipid content in hepatocytes), and for concomitant pre-diabetes (corrects hyperglycemia) [4]. However, the dyslipidemia that occurs in persons with NAFLD is a predictor for high cardiovascular risk (CVD) [5] and, according to the recommendations of the European Association for the Study of the Liver (EASL), European Association for the Study of Diabetes (EASD) and the European Association for the Study of Obesity (EASO) (2016) requires the prescribing of hypolipidemic pharmacotherapy [6]. Mostly, the statins are used with the purpose of correcting dyslipidemia. However, there is no unambiguousness about their recommending to patients with NAFLD because there is a notice of the probability of side effects due to hepatotoxicity [7]. Therefore, the search is relevant for alternative medicines to statins that would help to correct dyslipidemia, reduce hyperglycemia and have a hepatoprotective effect. Taking into account that NAFLD is a disease characterized by comorbidity, which often leads to polypharmacy [5], we should prefer the multifaceted action medicines for the treatment of such patients [8]. Despite the fact that modern recommendations [6] do not contain instructions about prescribtion of hepatoprotectors, there are papers $[9 ; 10 ; 11]$ on the expediency of their using, which is a pathogenetically grounded approach in case of NAFLD. It is proved that the correction of the functional state of hepatocytes contributes to increasing the efficiency of therapy due to indirect effects on the level of insulin resistance (IR) [9]. 
Table I. Laboratory characteristics of patients with non-alcoholic fatty liver disease and concomitant pre-diabetes (in comparison with patients who have non-alcoholic fatty liver disease with concomitant type 2 diabetes mellitus and in comparison with healthy persons)

\begin{tabular}{|c|c|c|c|}
\hline \multirow{2}{*}{$\begin{array}{l}\text { Groups, } \\
\text { The number of patients in the group (n) }\end{array}$} & \multirow{2}{*}{$\begin{array}{c}\text { Group 1, } \\
\text { NAFLD + pre-diabetes } \\
(n=55)\end{array}$} & \multirow{2}{*}{$\begin{array}{c}\text { Group 2, } \\
\text { NAFLD + T2-DM } \\
(n=73)\end{array}$} & \multirow{2}{*}{$\begin{array}{c}\begin{array}{c}\text { Group 3, } \\
\text { Healthy persons }\end{array} \\
(n=30)\end{array}$} \\
\hline & & & \\
\hline \multicolumn{4}{|c|}{ Laboratory test, units } \\
\hline Fasting glucose, $\mathrm{mM} / \mathrm{l}$ & $6,26 \pm 0,65 * \#$ & $11,1 \pm 1,78$ & $4,08 \pm 0,59$ \\
\hline $\mathrm{HbA} 1 \mathrm{C}, \%$ & $6,04 \pm 0,24 * \#$ & $7,87 \pm 0,52$ & $5,13 \pm 0,44$ \\
\hline IR-HOMA, U & $5,50 \pm 2,92$ & $9,34 \pm 3,42$ & $2,33 \pm 0,23$ \\
\hline Total cholesterol, mM/l & $5,18 \pm 0,56$ & $5,84 \pm 0,68$ & $4,03 \pm 0,66$ \\
\hline Triglycerides, mM/l & $2,54 \pm 0,41 \#$ & $2,77 \pm 0,6$ & $1,84 \pm 0,26$ \\
\hline $\mathrm{HDL}, \mathrm{mM} / \mathrm{I}$ & $1,17 \pm 0,12 * \#$ & $0,906 \pm 0,10$ & $2,27 \pm 0,76$ \\
\hline $\mathrm{LDL}, \mathrm{mM} / \mathrm{I}$ & $2,86 \pm 0,49$ & $3,67 \pm 0,47$ & $2,71 \pm 0,34$ \\
\hline VLDL, mM/l & $1,15 \pm 0,19$ & $1,26 \pm 0,27$ & $0,83 \pm 0,13$ \\
\hline Atherogenic index of plasma (AIP), U & $3,48 \pm 0,73$ \# & $5,48 \pm 0,68$ & $2,15 \pm 0,43$ \\
\hline ALT, IU/I & $27,55 \pm 6,93 \#$ & $37,9 \pm 10,52$ & $12,56 \pm 3,12$ \\
\hline AST, IU/I & $22,74 \pm 5,17 \#$ & $33,8 \pm 11,98$ & $8,32 \pm 2,89$ \\
\hline GGT, IU/I & $21,64 \pm 14,84$ & $39,3 \pm 12,55$ & $10,24 \pm 3,61$ \\
\hline Alkaline phosphatase (ALP), IU/I & $41,33 \pm 14,81 *$ & $94,81 \pm 14,05$ & $46,57 \pm 7,13$ \\
\hline Total protein, $\mathrm{g} / \mathrm{l}$ & $70,66 \pm 4,74$ & $70,6 \pm 3,03$ & $73,86 \pm 2,56$ \\
\hline Bilirubin total, mkM/l & $13,27 \pm 3,47$ & $9,74 \pm 1,82$ & $10,01 \pm 1,24$ \\
\hline Bilirubin direct, mkM/l & $3,85 \pm 0$ & $3,42 \pm 0,9$ & $3,4 \pm 0,76$ \\
\hline Creatinine, mkM/l & $77,54 \pm 19,56$ & $77,25 \pm 11,51$ & $78,91 \pm 8,22$ \\
\hline Uric acid, mM/l & $277,8 \pm 74,77$ & $336,2 \pm 53,97$ & $280,21 \pm 22,3$ \\
\hline
\end{tabular}

Note: * - significant differences with group $2, p \leq 0.05$; \#- significant differences with healthy persons, $p \leq 0.05$

Considering the complex action, cytoprotective, anti-inflammatory, hypotriglyceridemic and antioxidant properties, our attention was attracted by essential phospholipids (EFL) $[9 ; 12]$ and omega-3 polyunsaturated fatty acids (PUFAs). Building in the biological membrane of hepatocytes, EFL improve membrane-dependent functions, exhibit anti-inflammatory, anti-fibrotic, apoptotic modulating, regenerative, and protective effects [10]. The using of omega-3 PUFAs [13] is justified for the correction of hyperlipidemia, because they are characterized by hypotriglyceridemic action.

The frequent occurrence of NAFLD and the lack of unambiguous recommendations about the use of essential phospholipids and omega-3 PUFAs for their treatment determine the relevance of this work and justify the need to study their clinical efficacy in treatment of such patients.

\section{THE AIM}

The aim was to evaluate laboratory changes in the liver blood tests, carbohydrate and lipid metabolism in patients with NAFLD with concomitant pre-diabetes, and to study the feasibility of their complex treatment with the inclusion of omega-3 polyunsaturated fatty acids and essential phospholipids.

\section{MATERIALS AND METHODS}

This study is a part of common scientific theme of Therapy and Family Medicine Department "Optimization of prevention and treatment of obesity and diabetes mellitus in cases of Helicobacter pylori associated diseases". The article is also a part of scientific research work for obtaining a Doctor of Medicine degree "Non-alcoholic fatty liver disease and concomitant subclinical hypothyroidism". The study was carried out in accordance with the requirements of the Helsinki Declaration. The Ethical Committee of the Therapy and Family Medicine Department approved the study protocol, and informed consent was obtained from the participants.

We examined 55 patients with NAFLD and pre-diabetes that were treated at the Therapy and Family Medicine Department of Uzhhorod National University in 2011-2017. Their laboratory parameters were compared with similar indices of 73 patients with NAFLD and concomitant type 2 diabetes mellitus (T2-DM) (group 2) and 30 healthy persons, who were involved to the control group (group 3 ). The groups were standardized by the age and gender.

The NAFLD diagnosis was considered according to the EASL-EASD-EASO Clinical Practice Guidelines for the Management of Non-Alcoholic Fatty Liver Disease (2016). Inclusion criteria were confirmed diagnoses of NAFLD and pre-diabetes (glucose intolerance or preprandial hy- 
Table II. Dynamics of carbohydrate and lipid metabolism indices in patients with NAFLD and concomitant pre-diabetes under the influence of prescribed treatment $(\mathrm{M} \pm \mathrm{m})$

\begin{tabular}{|c|c|c|c|c|}
\hline \multirow[b]{2}{*}{ Blood test } & \multicolumn{2}{|c|}{ Sub-group $1 A(n=28)$} & \multicolumn{2}{|c|}{ Sub-group 1B $(n=27)$} \\
\hline & Before treatment & $\begin{array}{l}\text { After } 3 \text { month } \\
\text { treatment }\end{array}$ & Before treatment & $\begin{array}{l}\text { After } 3 \text { month } \\
\text { treatment }\end{array}$ \\
\hline Fasting glucose, mM/l & $6,28 \pm 0,65$ & $5,99 \pm 0,57$ & $6,23 \pm 0,66$ & $6,05 \pm 0,62$ \\
\hline $\mathrm{HbA} 1 \mathrm{C}, \%$ & $6,044 \pm 0,25$ & $5,92 \pm 0,23$ & $6,036 \pm 0,24$ & $5,96 \pm 0,23$ \\
\hline IR-HOMA, U & $4,69 \pm 2,39$ & $4,26 \pm 1,36$ & $6,32 \pm 3,35$ & $6,29 \pm 1,81$ \\
\hline Total cholesterole, mM/l & $5,19 \pm 0,65$ & $4,585 \pm 0,59 *$ & $5,18 \pm 0,47$ & $4,58 \pm 0,5 *$ \\
\hline Triglycerides, mM/l & $2,57 \pm 0,42$ & $2,23 \pm 0,37^{*}$ & $2,51 \pm 0,41$ & $2,06 \pm 0,34^{*}$ \\
\hline $\mathrm{HDL}, \mathrm{mM} / \mathrm{l}$ & $1,18 \pm 0,14$ & $1,32 \pm 0,10^{*}$ & $1,16 \pm 0,11$ & $1,22 \pm 0,06^{*}$ \\
\hline $\mathrm{LDL}, \mathrm{mM} / \mathrm{l}$ & $2,84 \pm 0,56$ & $2,24 \pm 0,47^{*}$ & $2,87 \pm 0,41$ & $2,42 \pm 0,47^{*}$ \\
\hline VLDL, mM/l & $1,16 \pm 0,20$ & $1,01 \pm 0,17^{*}$ & $1,15 \pm 0,19$ & $0,94 \pm 0,15^{*}$ \\
\hline Atherogenic index of plasma (AIP) & $3,47 \pm 0,82$ & $2,48 \pm 0,44^{*}$ & $3,5 \pm 0,64$ & $2,76 \pm 0,49^{*}$ \\
\hline
\end{tabular}

Note: * - significant difference with appropriative indexes before treatment, $p \leq 0,05$

Table III. Influence of treatment on biochemical blood parameters which characterize the liver and kidneys state

\begin{tabular}{ccccc}
\hline & \multicolumn{2}{c}{ Sub-group 1A (n=28) } & \multicolumn{2}{c}{ Sub-group 1B (n=27) } \\
\cline { 2 - 5 } Laboratory parameter & $\begin{array}{c}\text { Before } \\
\text { treatment }\end{array}$ & $\begin{array}{c}\text { After 3 month } \\
\text { treatment }\end{array}$ & $\begin{array}{c}\text { Before } \\
\text { treatment }\end{array}$ & $\begin{array}{c}\text { After 3 month } \\
\text { treatment }\end{array}$ \\
\hline ALT, IU/I & $27,68 \pm 4,96$ & $21,72 \pm 3,57^{*}$ & $27,4 \pm 8,61$ & $25,24 \pm 6,99$ \\
\hline AST, IU/I & $23,4 \pm 5,17$ & $18,54 \pm 3,75^{*}$ & $22,06 \pm 5,26$ & $21,57 \pm 5,17$ \\
\hline GGT, IU/I & $21,96 \pm 5,32$ & $16,63 \pm 3,99^{*}$ & $21,3 \pm 12,68$ & $19,0 \pm 13,34$ \\
\hline Alkaline phosphatase (ALP), IU/I & $44,14 \pm 13,56$ & $33,71 \pm 12,14^{*}$ & $38,41 \pm 15,73$ & $35,3 \pm 13,94$ \\
\hline Total protein, $\mathrm{g} / \mathrm{I}$ & $71,19 \pm 3,8$ & $75,38 \pm 2,34^{*}$ & $70,11 \pm 5,57$ & $66,16 \pm 3,01^{*}$ \\
\hline Bilirubin total, $\mathrm{mkM} / \mathrm{I}$ & $13,5 \pm 2,83$ & $12,25 \pm 2,04$ & $13,03 \pm 4,08$ & $12,96 \pm 3,32$ \\
\hline Bilirubin direct, $\mathrm{mkM} / \mathrm{I}$ & $3,98 \pm 0,77$ & $3,7 \pm 0,55$ & $3,7 \pm 0,61$ & $3,64 \pm 0,50$ \\
\hline Creatinine, $\mathrm{mkM} / \mathrm{I}$ & $76,7 \pm 11,74$ & $76,89 \pm 6,18$ & $78,42 \pm 25,5$ & $75,97 \pm 9,99$ \\
\hline Uric acid, $\mathrm{mM} / \mathrm{I}$ & $285,9 \pm 56,9$ & $245,7 \pm 41,91^{*}$ & $269,3 \pm 90,02$ & $268,4 \pm 90,57$ \\
\hline
\end{tabular}

Note: * - significant difference between parameters before and after treatment, $p \leq 0.05$

perglycemia). Exclusion criteria were viral, autoimmune, alcohol, and toxic liver disease, cardiovascular diseases decompensation, infectious diseases (including tuberculosis), and psychiatric diseases.

All patients were laboratory examined. Complex biochemical blood test included such indexes as total bilirubin level and its fractions, uric acid, total protein, albumin, creatinine rates; enzymes activity (alanine-aminotransferase (ALT), aspartate-aminotransferase (AST), gamma-glutamate transpeptidase (GGT), alkaline phosphatase (ALP). The lipid profile investigation included blood levels of total cholesterol (TC), triglycerides (TG); the high density lipoproteins (HDL), low density lipoproteins (LDL) and very low density lipoproteins (VLDL) cholesterol; atherogenic index of plasma (AIP) calculation. The carbohydrate metabolism was evaluated by fasting and postprandial blood glucose levels (oral glucose tolerance test - OGTT), glycated hemoglobin (HbA1C). Insulin resistence (IR) was evaluated by IR-HOMA index according to the formula IR-HOMA = (fasting blood glucose $\mathrm{X}$ fasting blood insulin) / 22.5, where X means multiplication and / means division.
The average laboratory tests in investigated group were calculated before the treatment start (baseline) and compared to ones in control group and to average laboratory indexes in patients with NAFLD and concomitant DM-2.

Medical treatment of all patients included life style modification with moderate exertion (walking for at least 30 min every day) and diet correction (5 food intakes daily: 3 large meals and 2 small ones; limited fast-digesting carbohydrates and animal fats consumption, enough water use, $15 \%$ deficit in daily caloric intake). According to prescribed pharmacotherapy all patients with NAFLD and concomitant pre-diabetes $(n=55)$ were divided into 2 sub-groups. Sub-group 1A included 28 patients that received EPL (medicine Essentiale Forte H) 2 capsules TID and omega-3 PUFA $1000 \mathrm{mg}$ daily. Sub-group 1B included 27 patients that received rosuvastatin (10 mg daily) for dyslipidemia correction. The efficacy of different combinations was evaluated after 3 month treatment by comparison the average laboratory tests with respective baseline tests. The remote consequences were estimated 12 months after the start of combined treatment by laboratory tests comparison to baseline, 3-month results and control group results. 
Table IV. Laboratory characteristics of long-term treatment results of patients with NAFLD and concomitant pre-diabetes

\begin{tabular}{|c|c|c|c|}
\hline \multirow{2}{*}{$\begin{array}{l}\text { Groups, } \\
\text { The number of patients in the group (n) }\end{array}$} & Sub-group $1 A$ & Sub-group 1B & Group 3 (healthy) \\
\hline & $(n=28)$ & $(n=27)$ & $(n=30)$ \\
\hline \multicolumn{4}{|c|}{ Laboratory test, units } \\
\hline Fasting glucose, mM/l & $5,52 \pm 0,48^{*}$ & $5,36 \pm 0,57^{*}$ & $4,08 \pm 0,59$ \\
\hline $\mathrm{HbA} 1 \mathrm{C}, \%$ & $5,78 \pm 0,20^{*}$ & $5,8 \pm 0,27^{*}$ & $5,13 \pm 0,44$ \\
\hline IR-HOMA, U & $3,44 \pm 0,87$ & $4,47 \pm 1,18$ & $2,33 \pm 0,23$ \\
\hline Total cholesterol, mM/l & $4,22 \pm 0,40^{*}$ & $4,15 \pm 0,35^{*}$ & $4,03 \pm 0,66$ \\
\hline Triglycerides, mM/l & $1,72 \pm 0,29 *$ & $1,55 \pm 0,14^{*}$ & $1,84 \pm 0,26$ \\
\hline $\mathrm{HDL}, \mathrm{mM} / \mathrm{l}$ & $1,36 \pm 0,07 *$ & $1,25 \pm 0,05 *$ & $2,27 \pm 0,76$ \\
\hline $\mathrm{LDL}, \mathrm{mM} / \mathrm{l}$ & $2,07 \pm 0,29 *$ & $2,2 \pm 0,32 *$ & $2,71 \pm 0,34$ \\
\hline $\mathrm{VLDL}, \mathrm{mM} / \mathrm{l}$ & $0,79 \pm 0,13 *$ & $0,71 \pm 0,06 *$ & $0,83 \pm 0,13$ \\
\hline Atherogenic index of plasma (AIP), U & $2,1 \pm 0,28 *$ & $2,33 \pm 0,33 *$ & $2,15 \pm 0,43$ \\
\hline ALT, IU/I & $16,7 \pm 2,65 *$ & $24,07 \pm 6,42 \#$ & $12,56 \pm 3,12$ \\
\hline AST, IU/I & $14,0 \pm 2,26 *$ & $20,46 \pm 5,20 \#$ & $8,32 \pm 2,89$ \\
\hline GGT, IU/I & $13,0 \pm 2,48 *$ & $17,86 \pm 9,37$ & $10,24 \pm 3,61$ \\
\hline Alkaline phosphatase (ALP), IU/I & $26,8 \pm 8,98 *$ & $36,9 \pm 15,84$ & $46,57 \pm 7,13$ \\
\hline Total protein, $\mathrm{g} / \mathrm{l}$ & $76,2 \pm 1,82 *$ & $63,56 \pm 3,03 *$ & $73,86 \pm 2,56$ \\
\hline Bilirubin total, $\mathrm{mkM} / \mathrm{l}$ & $10,65 \pm 1,31 *$ & $12,27 \pm 2,21$ & $10,01 \pm 1,24$ \\
\hline Bilirubin direct, mkM/l & $3,49 \pm 0,47$ * & $3,68 \pm 0,55$ & $3,4 \pm 0,76$ \\
\hline Creatinine, $\mathrm{mkM} / \mathrm{l}$ & $77,4 \pm 7,27$ & $75,3 \pm 9,16$ & $78,91 \pm 8,22$ \\
\hline Uric acid, $\mathrm{mM} / \mathrm{l}$ & $234,1 \pm 41,73 *$ & $256,8 \pm 77,03$ & $280,21 \pm 22,3$ \\
\hline
\end{tabular}

Note: * - significant difference with parameter before treatment; \# - significant difference with healthy, $p \leq 0.05$

The statistical analysis included Microsoft Excel table base of patients and Statistica 10.0 software use. Treatment group differences were evaluated using the independent sample t-test in case of normal distribution and Mann-Whitney test for non-parametric data. The significance of evaluated indices changes after treatment in normal distribution was evaluated using the Student's two-tailed test and in case of non-normal distribution - the Wilcoxon's test respectively. The difference was considered as significant in $p<0,05$. All quantitative indices were presented in $(\mathrm{M} \pm \mathrm{m})$ design where $M$ is a mean group value and $m$ is its mean deviation.

\section{RESULTS}

The results of this study demonstrate the laboratory changes in blood biochemical profile of patients with NAFLD and pre-diabetes (Table I).

This group of patients has not only disturbed carbohydrate metabolism, manifested by a significant increase in fasting glucose $(6.26 \pm 0.65 \mathrm{mmol} / \mathrm{l})$ and the level of glycosylated hemoglobin $(6.04 \pm 0.24 \%)$ compared with the group of healthy individuals (respectively $4.08 \pm 0.59 \mathrm{mmol} / \mathrm{l}$ and $5.13 \pm 0.44 \%$ ), which makes it possible to diagnose pre-diabetes, but also insulin resistance of peripheral tissues as demonstrated significantly higher index IR-HOMA (5.50 \pm 2.92$)$ in comparison with the healthy group $(2.33 \pm 0.23)$. The activity of alanine aminotransferase $(27.55 \pm 6.93 \mathrm{IU} / \mathrm{l})$ and aspartate aminotransferase $(22.74 \pm 5.17 \mathrm{IU} / \mathrm{l})$, which were significantly higher than the cor- responding indicators of healthy subjects in 2.2 and 2.73 times, indicated the presence of damage to hepatocyte membranes, which may lead to the development of a laboratory cytolysis syndrome. The presence of background for the occurrence of cholestasis is evidenced by the detected increase in GGTP activity, although the differences with healthy persons was not significant. There were no significant differences in the levels of total protein, bilirubin and its fractions, as well as the level of creatinine in patients with NAFLD compared to the control group of healthy individuals. Therefore, according to the results of this study, it cannot be stated that there is a disorder of the protein-synthetic function of the liver and pigmentary metabolism changes in patients with NAFLD and concomitant pre-diabetes. Renal dysfunction is also not confirmed.

The results of this study showed the clinical effectiveness of the use of essential phospholipids and omega-3 PUFA. The positive effect of both medicinal regimens (groups $1 \mathrm{~A}$ and 1B) on carbohydrate metabolism was revealed: there was a decrease in blood glucose level, glycosylated hemoglobin and a decrease in insulin resistance index, however, these changes were not significant (Table II). In both experimental subgroups, there were positive changes in the lipid profile, all indicators significantly changed compared with the baseline, without a significant difference in lipid profiles indexes between these groups after treatment. This fact testifies that the medicine regimen with including EFL and omega-3 PUFAs resulted in the same changes in lipid metabolism as the use of $10 \mathrm{mg}$ rosuvastatin daily (Table II). 
According to the results presented in Table III, the use of EFL and omega-3 PUFAs (subgroup 1A) resulted in a decrease in the activity of ALT by $21.5 \%$, AST by $20.77 \%$, GGTP by $24.3 \%$, alkaline phosphatase - by $23.6 \%$, and these changes were reliable $(\mathrm{p}<0.05)$.

Positive changes in laboratory parameters were observed not only immediately after the end of the 3-month course of treatment, but also after 12 months, that indicated the stability of the therapeutic effect (Table IV). At the same time, no significant changes were found between the laboratory tests results of healthy persons and patients in group $1 \mathrm{~A}$ in 12 month after treatment. In group $1 \mathrm{~B}$, the activities of ALT and AST in 12 months after treatment significantly differed from those of the healthy subjects. This fact indicates that there was no hepatoprotective effect in rosuvastatin.

\section{DISCUSSION}

Dyslipidemia was shown by significant changes in our patients triglycerides level, HDL cholesterol level, atherogenic factor and $22.2 \%$ higher compared to healthy person total cholesterol ones. The data is similar to results of other clinical studies $[2,8]$ and confirms the statement of current recommendations for diagnosis and treatment NAFLD (EASL-EASD-EASO, 2016) [6].

The prescription of EFL and omega-3 PUFA led to changes in liver blood tests of our patients. The revealed dynamics means positive hepatoprotective effect, which manifests itself in decreasing the intensity of the cytolysis and cholestasis syndromes. In addition, a significant increase $(\mathrm{p}<0.05)$ of the total protein level was observed under the influence of the combination of EFL and omega-3 PUFA, whereas under the influence of rosuvastatin it was significantly lowered. It probably means a positive influence of the combination of EPL and omega-3 PUFA on the liver protein-synthetic function. The same assumption was made by researchers $[3,9]$, who obtained similar application results. A significant decrease of uric acid was also found, that indicates positive effect of the combination of EPL and omega-3 PUFA on purine metabolism in patients with NAFLD and concomitant pre-diabetes. Similar changes of urine acid level under influence of same treatment was not declared in literature.

Consequently, according to results of our study, along with a hypolipidemic effect that does not significantly differ from the effect of rosuvastatin, the combination of an EFL with an omega-3 PUFA has a pronounced hepatoprotective effect. This fact gives grounds for recommending its use for patients with NAFLD in order to prevent the transition of hepatosteatosis (reverse stage) to steatohepatitis (irreversible stage).

Positive distant effects of treatment are explained, most likely, by the fact that during first 3 months of treatment patients develop a habit of leading the modified lifestyle and keeping on an adjusted diet, which remains after the end of the 3-month course of pharmacotherapy.

\section{CONCLUSIONS}

Along with the modification of lifestyle and dietary correction, it is advisable to prescribe medication for patients with non-alcoholic fatty liver disease and concomitant pre-diabetes. Inclusion of omega-3 polyunsaturated fatty acids and essential phospholipids into the therapeutic complex leads to an improvement in the laboratory pattern of these patients because it promotes not only correction of laboratory syndromes of cytolysis and cholestasis, as well as improvement of the glycemic profile, but also corrects dyslipidemia. Comprehensive treatment with the inclusion of these medicines can serve as a good alternative to rosuvastatin, since along with the hepatoprotective effect, it is characterized by both hypolipidemic and hypotriglyceridemic effects.

\section{REFERENCES}

1. Takahashi Y., Fukusato T. Histopathology of nonalcoholic fatty liver disease / nonalcoholic steatohepatitis. World Journal of Gastroenterology. 2014;20(42):15539-15548. doi: 10.3748/wjg.v20. i42.15539.

2. Schleicher J., Guthke R., Dahmen U. et al. A theoretical study of lipid accumulation in the liver-implications for nonalcoholic fatty liver disease. Biochimica et Biophysica Acta (BBA). 2014;1841(1):62-69. doi: 10.1016/j.bbalip.2013.08.016.

3. Stepanov Yu.M. The ese of essential phospholipids for the treatment of fatty liver disease. Gastroenterology. 2016;4(62):58-64. doi:10.22141/2308-2097.4.62.2016.81089.

4. Newsome P.N., Cramb R., Davison S.M. et al. Guidelines on the management of abnormal liver blood tests. Gut. 2018;67:6-19. doi:10.1136/gutjnl-2017-314924.

5. Patel P.J., Hayward K.L., Rudra R. et al. Multimorbidity and polypharmacy in diabetic patients with NAFLD: Implications for disease severity and management. Medicine (Baltimore). 2017;96(26):e6761. doi: 10.1097/ MD.0000000000006761.

6. EASL-EASD-EASO. Clinical Practice Guidelines for the management of non-alcoholic fatty liver disease. J Hepatol. 2016;64(6):1388-1402. doi: 10.1016/j.jhep.2015.11.004.

7. Argo C.K., Loria P., Caldwell S.H. et al. Statins in liver disease: A molehill, an iceberg, or neither? Hepatology. 2008;48(2):662-669. doi: 10.1002/ hep.22402.

8. Berlanga A., Guiu-Jurado E., Porras J.A. et al. Molecular pathways in nonalcoholic fatty liver disease. Clinical and Experimental Gastroenterology. 2014;7:221-239. doi:10.2147/CEG.S62831.

9. Dajani A., Abu Hammour A. Treatment of Nonalcoholic Fatty Liver Disease: Where do we Stand? An Overview. Saudi Journal of Gastroenterology. 2016;22(2):91-105. doi: 10.4103/1319-3767.178527.

10. Gundermann K.J., Gundermann S., Drozdzik M. et al. Essential phospholipids in fatty liver: a scientific update. Clinical and Experimental Gastroenterology. 2016;9:105-117. doi:10.2147/CEG.S96362.

11. Basu P.P., Shah N.J., Aloysius M.M. et al. Effect of Vitamin E and Alpha Lipoic Acid in Nonalcoholic Fatty Liver Disease: A Randomized, Placebo-Controlled, Open-Label, Prospective Clinical Trial (VAIN Trial). Open Journal of Gastroenterology. 2014;4:199-207. doi:10.4236/ ojgas.2014.45030.

12. Padma L., Mukaddam Q., Trailokya A. An Observational Study of Essentiale-Lin the treatment of Patients with Fatty Liver Disease. Indian Journal of Clinical Practice. 2013;23:735-739. 
13. Di Minno M.N., Russolillo A., Lupoli R. et al. Omega-3 fatty acids for the treatment of non-alcoholic fatty liver disease. World Journal of Gastroenterology. 2012;18:5839-5847. doi: 10.3748/wjg.v18.i41.5839.

This study is a part of common scientific theme of Therapy and Family Medicine Department "Optimization of prevention and treatment of obesity and diabetes mellitus in cases of Helicobacter pylori associated diseases" (No 0115U003904). The article is also a part of scientific research work for obtaining a Doctor of Medicine degree "Non-alcoholic fatty liver disease and concomitant subclinical hypothyroidism", researcher: Snizhana Feysa.

\section{ORCID and contributionship:}

Snizhana V. Feysa: 0000-0002-5064-8222 A,B,C,D,F

Svitlana O. Rudakova: 0000-0001-9129-4523 ${ }^{E, F}$

\section{Conflict of interest:}

The Authors declare no conflict of interest.

\section{CORRESPONDING AUTHOR}

Snizhana V. Feysa

Uzhhorod National University

148 Sobranecka st., 88017 Uzhhorod, Ukraine

tel.: + 380505600847

e-mail:snizhana.feysa@uzhnu.edu.ua

Received: 07.11 .2020

Accepted: 04.03 .2021

A - Work concept and design, B - Data collection and analysis, C - Responsibility for statistical analysis,

D-Writing the article, $\mathbf{E}$-Critical review, $\mathbf{F}$ - Final approval of the article 